\title{
Image and clinical aspects of congenital Zika Syndrome in 24-month-old girl
}

Maria Suelly Nogueira Pinheiro $1 *$, Gabriele Sousa Barbosa 1, Rondineia de Jesus Silva 1, Vamberto Benício de Oliveira Júnior 1, Lucas Vinicius Gomes Silva 1, Liane Carvalho de Brito de Souza 1, Josenília

Maria Alves Gomes 1, Washington Aspilicueta Pinto Filho 1, 2, Carlos Eduardo Barros Jucá 2

${ }^{1}$ Walter Cantídio University Hospital, Federal University of Ceará, Fortaleza, CE, Brazil.

${ }^{2}$ Albert Sabin Children's Hospital, Fortaleza, CE, Brazil.

${ }^{*}$ Corresponding author: Maria Suelly Nogueira Pinheiro. Rua Pastor Samuel Munguba, 1290 - Rodolfo Teófilo. Zip Code: 60430-372-Ceará, CE, Brazil. Phone: +55(85) 99686-9181. E-mail: msuellynogueirap@alu.ufc.br.

Research Ethics Committee Approval (if necessary): Approved by the Hospital Infantil Albert Sabin Ethics Committee (\#2.314.838).

Received on: Nov 3, 2021. Accepted on: Nov 19, 2021. Available online: Jan 22, 2022.

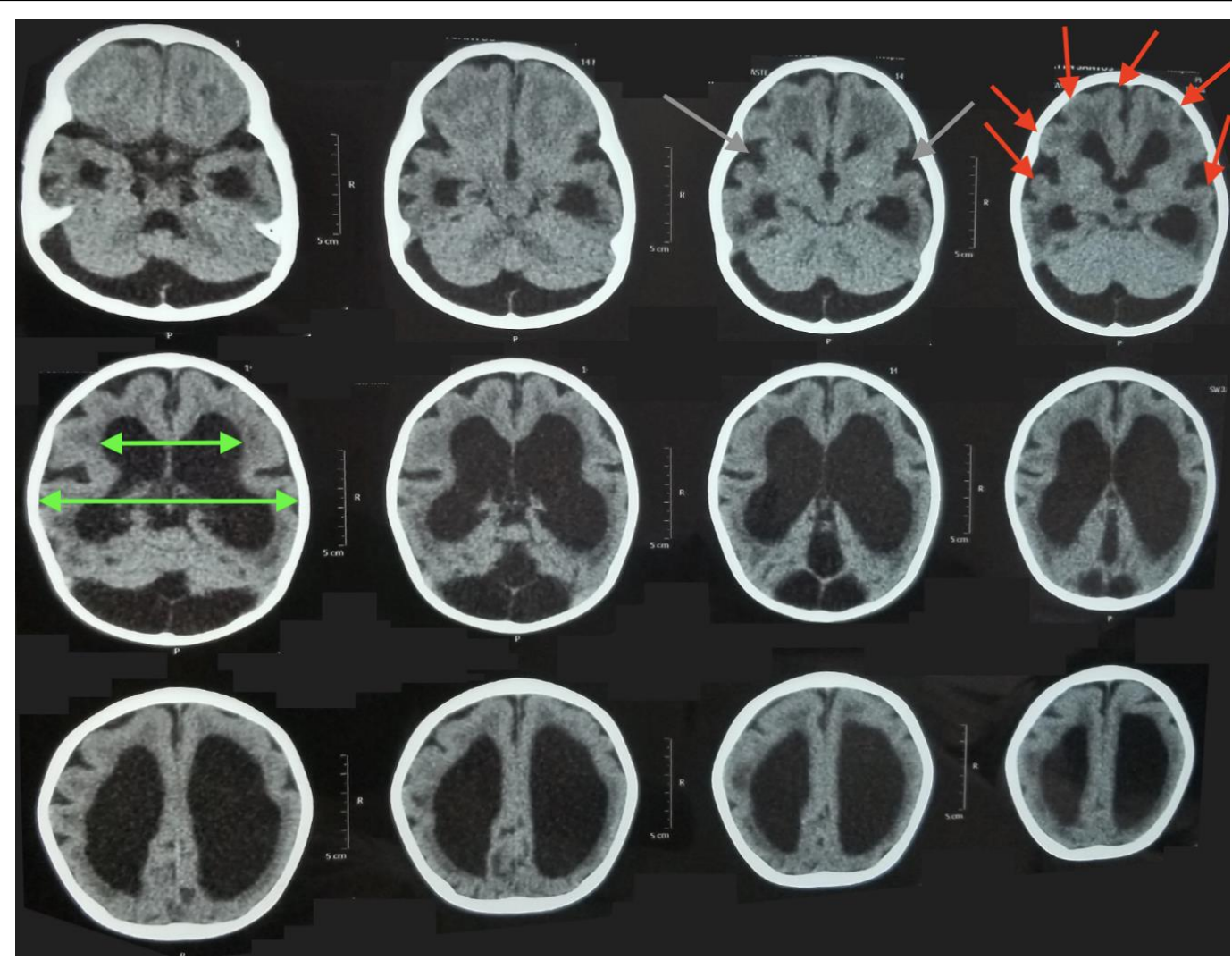

Figure 1. Computerized tomography of a 24-month-old girl diagnosed with Congenital Zika Syndrome (CZS), showing cortical and subcortical atrophy (examples shown by gray arrows), polymycrogyria (red arrows), and severe ventriculomegaly (exampled by the green lines measuring and showing the ratio between the maximal diameter of the frontal horns and the maximal diameter of the internal skull, Evans' Index $>0.3$ ). 
In the following clinical image report, the tomographical findings and evolution of a girl with Congenital Zika Syndrome are presented and further explained, alongside a few pathological facts about the disease itself. The patient was 24 months-old at the time of admittance, was $13 \mathrm{~kg}$ (28.6 lb) and had already had a previous CZS diagnosis, given following her birth. The chief complaint was of recent heightened somnolence and increased irritability, as observed by her parents. Her head circumference $(\mathrm{HC})$ at the time was 40 cm (z-score <-3 SD), with an ICP of 15 $\mathrm{cm}$ of $\mathrm{H} 2 \mathrm{O}$.

During clinical investigation, a computerized tomography (CT) was made, as shown by the image above. The patient's CT scan shows the cardinal aspects of a Congenital Zika Syndrome case. In figure 1, it is possible to see cortical and subcortical atrophy, cortical malformation manifesting as polymicrogyria - a plethora of seemingly shrunk gyres -, as well as severe ventriculomegaly resulted from the presence of communicating hydrocephalus. Other radiological hallmarks of CZS include calcified nodule-like regions in the subcortical area and basal ganglia, cerebellar malformations and subdural space expansion [1].

Indeed, her Evans' Index was 0.5 before any intervention was performed, higher than the the 0.3 cut-off limit cited throughout the literature surrounding the subject, further confirming the ventricle volume enlargement [2]. The patient was submitted to ventricular shunt insertion in order to subsidize the hydrocephalus, to which she reacted well, with clinical improvement regarding the initial symptoms and without any further complications.

It is also important to mention that, given the still current nature of the Zika virus (ZIKV) outbreak, the clinical spectrum of CZS is still in expansion, as patients can evolve differently throughout their years of development. Hydrocephalus and ventriculomegaly, both present in this case, may not appear at birth, but rather later, commonly around the end of the first year of life, entailing either progressive cerebral injury or, in this case, a rather sudden clinical worsening [3].

Other symptoms that make up CZS include microcephaly, present in all cases of patients with the syndrome, further distinguished by craniofacial disproportion noted at birth, which may also be accompanied by occipital bone prominence and excessive scalp skin. In this aspect, it is also important to cite a few main clinical findings of CZS patients that develop hydrocephalus, such as irritability and drowsiness (shown in the case), but also inability to maintain visual fixation and pursuit, dysphagia, hypertonia and severe delay in the achievement of developmental milestones [3].

In conclusion, in this report, the main image findings of Congenital Zika Syndrome were exposed, and a few clinical findings of the syndrome were briefly discussed. The nature of CZS as a pathology with a still evolving clinical spectrum was mentioned, thus highlighting the need for further and more complex studies on the subject. 


\section{References}

[1] Jucá E, Pessoa A, Ribeiro E, Menezes R, Kerbage S, Lopes T, Cavalcanti LP. Hydrocephalus associated to congenital Zika syndrome: does shunting improve clinical features? Childs Nerv Syst. 2018 Jan;34(1):101-106. doi: 10.1007/s00381017-3636-2.

[2] Sarı E, Sarı S, Akgün V, Özcan E, İnce $S$, Babacan $O$, Saldır M, Açıkel C, Başbozkurt G, Yeşilkaya Ş, Kılıc C, Kara K, Vurucu S, Kocaoğlu M, Yeşilkaya E. Measures of ventricles and evans' index: from neonate to adolescent. Pediatr Neurosurg. 2015;50(1):12-7. doi: $10.1159 / 000370033$.

[3] van der Linden V, de Lima Petribu NC, Pessoa A, Faquini I, Paciorkowski $\mathrm{AR}$, van der Linden $\mathrm{H}$ Jr, SilveiraMoriyama L, Cordeiro MT, Hazin AN, Barkovich AJ, Raybaud C, de Brito Abath M, Ribeiro E, Barros Jucá CE, Aragão MFVV, Coelho Travassos PT, Jungmann P. Association of Severe Hydrocephalus With Congenital Zika Syndrome. JAMA Neurol. 2019 Feb 1;76(2):203-210. doi: 10.1001/jamaneurol.2018.3553.

Conflict of interest: The author declares no conflicts of interest.

Acknowledgements: To Prof. Dr. Eduardo Jucá for supplying the clinical details of this case.

Funding: List here the financial support received for the research.

How to cite this article: Pinheiro MSN, Barbosa GS, Silva RJ, de Oliveira Júnior VB,Silva LVG, Souza LCB, Gomes JMA,
Pinto Filho WA, Jucá CEB. Image and clinical aspects of congenital Zika Syndrome in 24-month-old girl. Brazilian Journal of Case Reports. 2021 Oct-Dec;01(4):44-46. 